\title{
Research on Deformation Characteristics of Single Bubble
}

$$
\text { Ling-Jun } \mathrm{XU}^{1, \mathrm{a}} \text {, Yang } \mathrm{XUE}^{2} \text {, Gang } \mathrm{CHEN}^{3} \text {, Song } \mathrm{ZHANG}^{4}
$$

1,2 Hydro china Hua dong Engineering Corporation, Hangzhou, China, 310014

\author{
${ }^{3}$ College of water conservancy and hydropower engineering, Xi'an University of Technology, Xi'an; \\ China, 710048 \\ ${ }^{4}$ Sichuan Water Conservancy Vocational College, Chengdu, China, 611231 \\ axulingjun@163.com
}

\begin{abstract}
Keywords: Coupled Level Set and Volume of Fluid Method, Continuum Surface Tension Force Model, Model Test, Numerical Simulation, Bubble Deformation.
\end{abstract}

\begin{abstract}
The rising behavior of single bubble is investigated in $0.134 \leq \mathrm{Eo} \leq 8.588 ; 0.82 \leq \mathrm{We} \leq 4.83$ and $0.5 \leq \mathrm{Ta} \leq 3.6$ by means of CLSVOF method and CSF model. The new empirical relations are obtained by comparing experimental data, simulated data and the empirical relations of scholars. The three formulas can describe the bubble deformation more accurate. The new empirical relations provide a lower boundary of scope of application and provided reference to bubble research.
\end{abstract}

\section{Introduction}

Aerated flow[1] is a main flow phenomenon in high speed flow, the key and difficult problem is how to simulate and measure its complex bubble flow. Due to different bubble deformation and existence periodic length, Bubble formation, growth and movement process[2][3] show a different geometric structures and complicated hydrodynamic characteristics[4][5] Therefore, a thorough study of bubble movement is very important to extend bubble application field.

The experiments and theoretical research have been carried out by scholars in the middle of last century, some have tried to correlate the aspect ratio $\mathrm{E}[6][7]$ as a function of a dimensionless parameter which could group the experimental data using Eo[8][9], We and Ta[10][11]. Ruzicka[12] studied bubble behavior by asymptotic expansion method, and analyzed the small deformation during the rising process. Raymond[13] investigated the rising behavior of bubble in liquid with different viscosity by model tests, and described bubble shape and aspect ratio using dimensionless parameters. Tomiya$\mathrm{ma}[14]$ found that terminal velocity and the ratio of length to width is inversely proportional to the relationship. Churchill[15] proposed that a parameter which can describe the bubble deformation played an important academic role. Taylor[16] described bubble deformation using the relation of We, Eo and E.

In order to make the research has universal significance, we select a group of characteristic quantity and handle variables by dimensionless method. The empirical expressions of dimensionless parameters are as follows:

$$
E o=\frac{\left(\rho_{f}-\rho_{b}\right) g d^{2}}{\sigma} ; W e=\frac{\rho_{f} U^{2} d}{\sigma} ; E=\frac{a}{b} ; \mathrm{Ta}=\operatorname{Re} \times M^{0.23} ; M o=\frac{\left(\rho_{f}-\rho_{b}\right) g \mu_{f}^{4}}{\rho_{f}^{2} \sigma^{3}}
$$

where $a$ is the miner length of bubble, $b$ is the major length of bubble.

The rising behavior of single bubble is investigated by means of CLSVOF method and CSF model. combing with dimensionless parameters, the new bubble deformation relation are deduced which provide reference to bubble research.

\section{Calculation Model}

The gas-liquid interface is tracked by coupled level set and volume of fluid method, The control equations are shown below. 
continuity equation: $\frac{\partial \rho}{\partial t}+\nabla \cdot(\rho u)=0$

momentum equation: $\frac{\partial(\rho u)}{\partial t}+\nabla \cdot(\rho u u)=-\nabla p+\nabla \cdot \mu\left[\nabla u+(\nabla u)^{T}\right]+\rho g+F_{\sigma}$

where $\mathrm{u}$ is velocity, $\rho$ is density, $\mathrm{p}$ is pressure, $\mu$ is viscosity, $\mathrm{g}$ is acceleration of gravity, $F_{\sigma}$ is body force of surface tension obtained by CSF method.

VOF equation: $\frac{\partial \alpha_{q}}{\partial t}+u \cdot \nabla \alpha_{q}=0$

where $\alpha_{q}$ is the volume fraction of $\mathrm{q}, \mathrm{q}$ is gas phase or liquid phase.

Level Set equation: $\frac{\partial \varphi}{\partial t}+u \cdot \nabla \varphi=0$

that is $\varphi>0$ if in gas region, $\varphi<0$ if in liquid region, $\varphi=0$ if on the interface, and the magnitude of $\varphi$ equals to the distance to the interface.

The body force $F_{\sigma}$ equation: $F_{\sigma}=\sigma \kappa(\varphi) \delta(\varphi) \nabla \varphi$

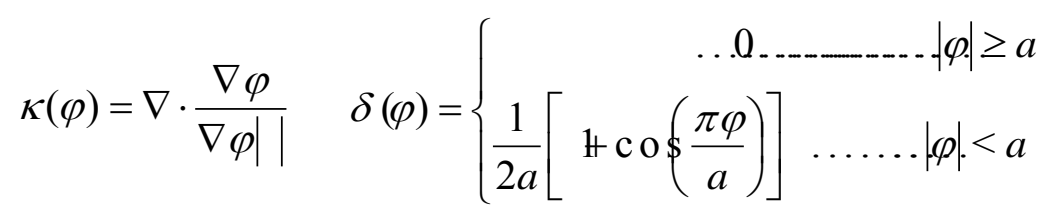

where $\sigma$ is surface tension, $\kappa(\varphi)$ is the mean curvature, $\delta(\varphi)$ is the Delta function which translate the force from surface force into body force, a is the interface thickness.

The mixture equation: $\rho(\varphi)=\rho_{g}+\left(\rho_{l}-\rho_{g}\right) H(\varphi)$

$$
\begin{aligned}
& \mu(\varphi)=\mu_{g}+\left(\mu_{l}-\mu_{g}\right) H(\varphi)
\end{aligned}
$$

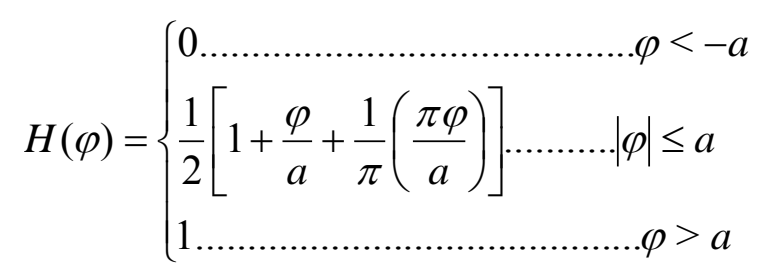

where subscripts $g$ and 1 denote the gas phase and liquid phase

The governing equations for this model were solved using the commercial CFD.

\section{Results and Discussion}

Figure 1 and Figure 2 shows the bubble aspect ratio changes with the increase of rising height in model test and numerical simulation. In research, The range of dimensionless Eo of bubble is $0.134 \sim 3.355$. It can be seen from the comparison results that the aspect ratio E decreases rapidly in early rise, after falling to a minimum value, E shows a vibration form, and the vibration amplitude decreases with increase in rising height. It is in well agreement with model results and simulated results which means that the simulated results are believable.

Tomiyama observed that the aspect ratio, which depends on the magnitude of initial shape oscillation, has strong correlation with the Weber number. The aspect $\mathrm{E}$ in correlation with Eo mostly rely on different bubble forming methods in the model test of small bubble. Okawa[17]and Wellek[18] de- 
scribed the deformation of bubble and water drop through the dimensionless number .Wellek correlation which was originally developed for non oscillating drops in contaminated liquids, appears to be extendible even to oscillating bubbles in low viscosity liquids. Later, Okawa modified the Wellek correlation, providing a lower boundary of their data. The two correlations are as follows:

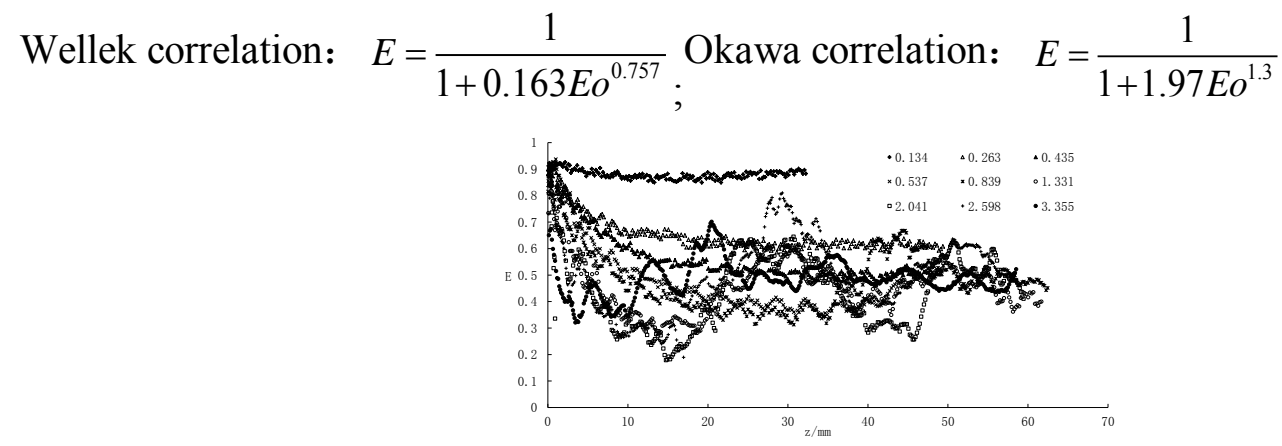

Fig. 1. The Aspect Ratio E Changes along Rising Height(Simulated Data)

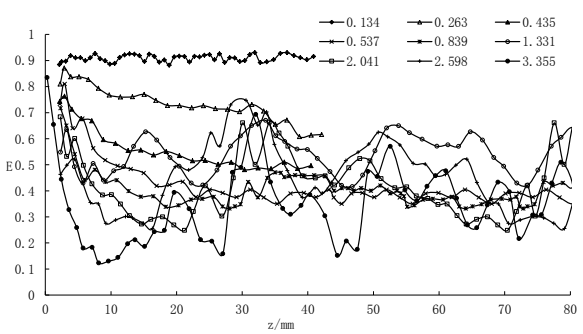

Fig. 2.The Aspect Ratio E Changes along Rising Height(Model Data)

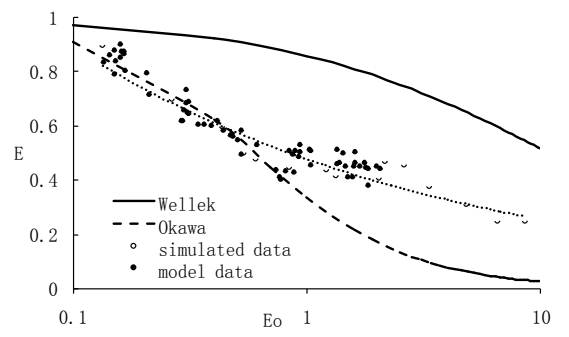

Fig. 3 Aspect Ratio E Versus Eo Number of Bubble

The comparison between the above correlations, model data and simulated data is shown in Figure3, where $\mathrm{E}$ is plotted against Eo. The overall trend of $\mathrm{E}$ is decrease with the increase in Eo, and gradually comes to a standstill. It can be seen from the comparison of the four that Wellek correlation is different with others, which means Wellek correlation can describe deformation of water drop, but not suitable for bubble deformation in water, Wellek correlation provides an inaccuracy result in water, Okawa correlation do better than Wellek correlation in the range of Eo $\leq 0.75$, but when Eo $>0.75$, most of values which calculated from correlation are lower than actual value, the deviation amplitude increases with increase in Eo, so, we provide a new correlation to describe the characteristics of bubble deformation, it can describe the relationship more accurately between E and Eo in the scope of $0.134 \leq$ Eo $\leq 8.588$. The new correlation is as follows:

$$
E=\frac{1}{0.4778 E o^{0.269}}
$$

As same as Eo, We is a dimensionless parameter used to describe bubble deformation and it is the relation between the inertia force and surface tension. A lot scholars[19] provided that bubble deformation affected by inertia and surface tension. Moore[20] noted that for $\operatorname{Re}>200$ the shape is independent of viscous effect, derived the following model: 


$$
\mathrm{We}=4 \mathrm{E}^{1 / 3} \frac{\left(1+\mathrm{E}^{2}-2 \mathrm{E}^{3}\right)\left[\cos ^{-1} \mathrm{E}-E\left(\sqrt{1-E^{2}}\right)\right]^{2}}{\left(1-E^{2}\right)^{3}}
$$

The below formula can be obtained by Taylor series expansion: $\quad E=\frac{1}{1+9 \mathrm{We} / 64}$

Taylor[21] proposed a model for creeping flow (low Reynolds number) which can be developed as a series:

$$
\mathrm{E}=\frac{1}{1+5 \mathrm{We} / 32}
$$

Wellek[22] proposed the following correlation based on We: $E=\frac{1}{1+0.091 \mathrm{We}^{0.95}}$

Raymond[23] proposed a correlation suitable for serious deformation: $E=1-\mathrm{We} / 9$

Figure 4 shows the plot of $\mathrm{E}$ as a function of We, along with predictions provided by Wellek, Moore, Taylor, Raymond, model data and simulated data.

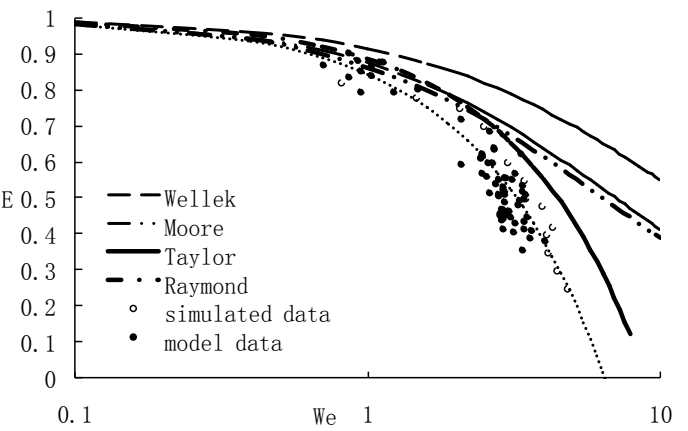

Fig. 4 Aspect Ratio E versus We Number of Bubble

In Fig4, the correlations shows satisfactory results except Wellek correlation when $\mathrm{We} \leq 1.5$, all predict results are higher than model data and simulated data when $\mathrm{We}>1.5$. Raymond correlation result gets close to model data and simulated data, but there still exists a few deviation. Here we provide a new correlation to describe the characteristics of bubble deformation, it is suitable for bubble deformation in the scope of $0.82 \leq \mathrm{We} \leq 4.83$. The new correlation is as follows: $\mathrm{E}=1-2 \mathrm{We} / 13$.

In order to find a dimensionless parameter which can describe bubble deformation accurately, Tadaki[24] induced Ta to describe bubble deformation. Ta is the monotone function of Re and Mo, Tadaki provided that the bubble shape can be determined from the balance among surface tension, inertial and gravity forces; viscous forces are negligible. The Tadaki correlation is expressed as follows:

$$
\mathrm{E}^{1 / 3}=\left\{\begin{array}{cc}
1 & \mathrm{Ta}<2 \\
1.14 \mathrm{Ta}^{-0.176} & 2<\mathrm{Ta}<6 \\
1.36 \mathrm{Ta}^{-0.28} & 6<\mathrm{Ta}<16.5 \\
0.62 & 16.5<\mathrm{Ta}
\end{array}\right.
$$

Vakhrushev [25] modified the Tadaki correlation in $\mathrm{Mo}<10^{-3}$, it is as follows:

$$
\mathrm{E}=\left\{\begin{array}{cc}
1 & \mathrm{Ta}<1 \\
\{0.81+0.206 \tanh [2(0.8-\lg T a)]\}^{3} & 1<\mathrm{Ta}<39.8 \\
0.24 & 39.8<\mathrm{Ta}
\end{array}\right.
$$

Fan and Tsuchiya[26] provided a group of coefficient which can be used in pure water: 


$$
\mathrm{E}=\left\{\begin{array}{cc}
1 & \mathrm{Ta}<0.3 \\
\left\{0.77+0.24 \tanh \left[1.9\left(0.40-\log _{10} T a\right)\right]\right\}^{2} & 0.3<\mathrm{Ta}<20 \\
0.30 & 20<\mathrm{Ta}
\end{array}\right.
$$

Figure 5 shows the plot of $\mathrm{E}$ as a function of Ta, along with predictions provided by Tadaki, Vakhrushev, Fan, model data and simulated data.

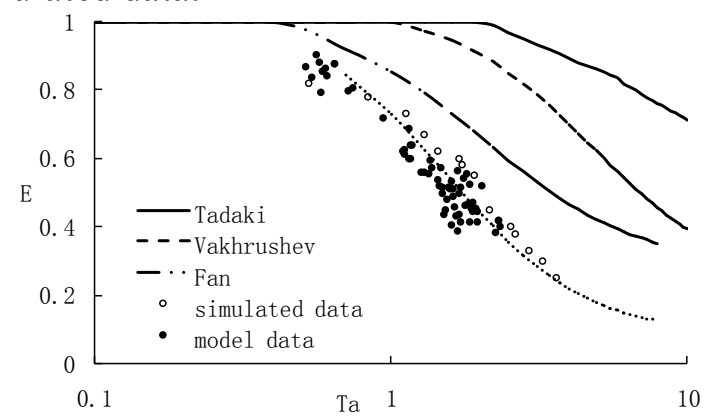

Fig. 5 Aspect Ratio E versus Ta Number of Bubble

It can be seen from Fig4 that the results of three correlations are higher than model data and simulated data, The Fan correlation gets close to the result of paper, but the deviation can not be neglected. We obtained new correlation on the base of Fan correlation. It is suitable for description of bubble deformation in water.

$$
\mathrm{E}=\left\{\begin{array}{cc}
1 & \mathrm{Ta}<0.5 \\
\left\{0.77+0.24 \tanh \left[1.9\left(0.40-\log _{10} T a\right)\right]\right\}^{4} & 0.5<\mathrm{Ta}<3.6 \\
0.30 & 3.6<\mathrm{Ta}
\end{array}\right.
$$

\section{Conclusion}

Part of Eo and We between model data, simulated data in paper and the empirical formula given by scholars agree with each other, Okawa correlation and Raymond correlation get better result when $\mathrm{Eo} \leq 0.75$, We $\leq 1.5$. It is difficult to confirm which dimensionless parameter is suitable for bubble deformation. By fitting bubble parameters, we obtain new correlations which are consist of E, Eo, We and Ta. The three correlations can describe bubble deformation accurately in conditions of $0.134 \leq \mathrm{E} 0 \leq 8.588,0.82 \leq \mathrm{We} \leq 4.83$ and $0.5 \leq \mathrm{Ta} \leq 3.6$.

\section{References}

[1]H. TSUGE, Hydrodynamics of bubble formation from submerged orifices, Encyclopedia of Fluid Mechanics (1986) 191-232 (Chapter 9).

[2]F. PEEBLES, H. GARBER, Studies on the motion of gas bubbles in liquid, Chemical Engineering Progress 49 (2) (1953) 88-97.

[3]A. SATYNARAYAN, R. KUMAR, N.R. KULOOR, Studies in bubble formation-II. Bubble formation under constant pressure conditions, Chemical Engineering Science 24 (1969) 749-761.

[4]J.R. GRACE, T. WAIREGI, T.H. Nguyen, Shapes and velocities of single drops and bubbles moving freely through immiscible liquids, Transactions of the IChemE 54 (1976) 167.

[5]A. TOMIYAMA, K. MIYOSHI, H. TAMAI, I. ZUN, T. SAKAGUCHI, A bubble tracking method for the predictions of spatial-evolution of bubble flow in a vertical pipe, in: Proceedings of the 3rd International Conference on Multiphase Flows (CD-ROM), Lyon, 8-12 June, 1998. 
[6]F. PEEBLES, H. GARBER, Studies on the motion of gas bubbles in liquid,Chemical Engineering Progress 49 (2) (1953) 88-97.

[7]A. SATYNARAYAN, R. Kumar, N.R. Kuloor, Studies in bubble formation-II. Bubble formation under constant pressure conditions, Chemical Engineering Science 24 (1969) 749-761.

[8]T. OKAWA, T. TANAKA, I. KATAOKA, M. Mori, Temperature effect on single bubble rise characteristics in stagnant distilled water, International Journal of Heat Mass Transfer 46 (2003) 903-913.

[9]R.M. WELLEK, A.K. AGRAWAL, A.H.P. SKELLAND, Shape of liquid drops moving in liquid media, AIChE Journal 12 (1966) 854-862.

[10]T. TADAKI, M. MAEDA, On the shape and velocity of single air bubbles rising in various liquids, Kagaku Kogaku 25 (1961) 254-264 (also cited by Fan and Tsuchiya.

[11]L.S. FAN, K. TSUCHIYA, Bubble Wake Dynamics in Liquids and Liquid-Solid Suspensions, Butterworth Heinemann, Oxford, 1990.

[12]M.C. RUZICKA, On bubbles rising in line, International Journal of Multiphase Flow 26 (2000) $1141-1181$.

[13]RAYMOND F, ROSANT J M. A numerical and experimental study of the terminal velocity and shapeOf bubbles in viscous liquids[J]. ChemicalEngineeringSCI,2000,55(5):943-955.

[14]A. TOMIYAMA, S. YOSHIDA, S. HOSOKAWA, Surface tension force dominant regime of single bubbles rising through stagnant liquid, UK-Japan Seminar on Multiphase Flow (2001).

[15]CHURCHILL S W.A theoretical structure and correlating equation forthe motion of single bubbles, Chem. Eng. Process 26 (1989) 269-279.

[16]TAYLOR T D, ACRIVOS A. On the deformation and drag of a fallingviscous drop at low Reynolds number[J]. Fluid Mech.1964, 18 :466-476.

[17]OKAWA T, TANAKA T, KATAOKAI, MORI M. Temperature effect onsingle bubble rise characteristics in stagnant distilled water, Int. J.Heat Mass Transfer,2003, 46: 903-913.

[18]WELLEKR M, AGRAWAL A K, SKELLAND A H P. Shape of liquid dropsmoving in liquid media[J]. AIChE J. 1966, 12: 854-862.

[19]DI MARCO P, GRASSI W, MEMOLI G. Experimental study on rising velocity of nitrogen bubbles in FC-72[J]. International Journal of Thermal Sciences, 2003, 42:435-446.

[20]MOORE D W.The velocity rise of distorted gas bubbles in a liquid ofsmall viscosity[J]. Fluid Mech,1965, 23 (4): 749-766.

[21]TAYLOR T D, Acrivos A. On the deformation and drag of a fallingviscous drop at low Reynolds number[J]. Fluid Mech. 1964,18: 466-476.

[22]WELLEKR M, AGRAWALA K, SKELLANDA H P. Shape of liquid dropsmoving in liquid media, AIChE[J]. 12 (1966) 854-862.

[23]RAYMOND R, ROSANT J M. A numerical and experimental study of the terminal velocity and shape of bubbles in viscous liquids[J]. Chem Eng Sci, 2000, 55(5):943-955

[24]TADAKI T, MAEDAM. On the shape and velocity of single air bubblesrising in various liquids[J]. Kagaku Kogaku,1961, 25: 54-264.

[25]VAKHRUSHEV A I, EFREMOV G I. CHEM. Techn. Fuel Oils (USSR), 1970, 5: 376-379.

[26]FAN L S, TSUCHIYA K. Bubble Wake Dynamics in Liquids andLiquid-Solid Suspensions[M]. Butterworth-Heinemann, Oxford, 1990. 